\title{
4-Etoksi-3-Metoksibenzaldehit Molekülünün Hesaplamalı Kimya Yöntemiyle Kimyasal Aktivite Tayini
}

\author{
Serap UZUN ${ }^{*}$, Zeynep DEMIRCIOĞLU²
}

${ }^{1}$ Samsun Üniversitesi, Mühendislik Fakültesi Temel Bilimler Bölümü, Samsun, Türkiye

${ }^{2}$ Sinop Üniversitesi, Fen Edebiyat Fakültesi Fizik Bölümü, Sinop, Türkiye

Geliş Tarihi:09.10.2019

*Sorumlu Yazar: serap.uzun@samsun.edu.tr Kabul Tarihi:20.10.2019

\section{$\ddot{O ̈ z}$}

4-Etoksi-3-Metoksibenzaldehit molekülü biyolojik aktivitelerinin yanı sıra hetero halkalı bileşiklerin sentezlenmesinde oldukça büyük bir öneme sahiptir. X-ışınları çalışması Leka ve ark. tarafından incelenmiş olan bu molekülün kuramsal hesaplamaları Yoğunluk Fonksiyonel Kuramı (YFK), B3LYP modeli ve 6-311G(d,p) baz seti seçilerek yapılmıştır. Çalışılan yapının optimizasyonu sonucunda elde edilen geometrik parametrelerin X-1şınları sonucunda elde edilenleri başarılı bir şekilde temsil ettiği görülmüş ve tüm kuramsal hesaplamalar aynı yöntem ile yapılmıştır. Optimize yapıya ait kimyasal aktivite parametreleri, moleküler elektrostatik potansiyel haritası, Fukui fonksiyonları ve net yük analizi yapılarak yapının elektrofilik ve nükleofilik doğasının yanı sıra setlik ve yumuşaklık bilgisine ulaşılmıştır. Lineer olmayan optik özellikleri incelenerek yapının optik bir materyal olma eğilimi tartışılmıştır. Bunların yanı sıra DNA bazları olan adenin, guanin, sitozin ve timinin çalışılan molekül ile olan etkileşimleri elektrofilik merkezli yük transferi (ECT) yöntemi ile belirlenmiştir.

Anahtar Kelimeler: Yoğunluk Fonksiyonel Kuramı, Lineer Olmayan Optik Özellikler, Kimyasal Aktivite Parametreleri.

\section{Chemical Activity Determination of 4-Ethoxy-3-methoxybenzaldehyde Molecule by Computational Chemical Method}

\begin{abstract}
The 4-ethoxy-3-methoxybenzaldehyde molecule is of great importance in the synthesis of hetero-ring compounds as well as biological activities. X-ray diffraction analysis is made by Leka and friends and theoretical results are calculated by density funct,onal theory, B3LYP model and 6-311G(d,p) bases set. The geometric parameters obtained as a result of the optimization of the structure were successfully represented by X-ray diffraction method and all theoretical calculations are used by the the same method of DFT/B3LYP/6-311G(d,p). Chemical activity parameters of the optimized structure, molecular electrostatic potential map, Fukui functions and net charge analysis were used to obtain electrophilic and nucleophilic nature of the structure as well as hardness and softness information. Nonlinear optical properties were examined and the tendency of the structure to be an optical material was discussed. In addition, the interactions of DNA bases adenine, guanine, cytosine and thymine with the studied molecule were determined by electrophilic charge transfer (ECT) method.
\end{abstract}

Keywords: Density Functional Theory, Non Linear Optic Properties, Chemical Activity Parameters. 


\section{Giriş}

Dehidrozin türevi bileşiklerin biyolojik aktiviteleri ve hetero yapılı bileşiklerin sentezinde sıkça kullanıldığı literatürde mevcut çok sayıda çalışmada belirtilmektedir (Leka ve ark., 2013; Tatsuzaki ve ark., 2006; Kubra ve ark., 2013). Sentezi ve X-1şınları çalışması yapılmış olan 4-etoksi-3metoksibenzaldehit molekülünün litearürde kuramsal çalışmasına rastlanamamıştır (Leka ve ark. 2013). Bu çalışmanın amacı Yoğunluk Fonksiyonel kuramını kullanarak yapının kimyasal aktivitesinin ve lineer olmayan optik özelliğinin belirlenmesidir.

Moleküler yapının en kararlı Yoğunluk Fonksiyonel Kuramı (YFK) kullanılarak Becke-tipi 3parametreli Lee-Yang-Parr modeli B3LYP ve 6-311G(d,p) baz seti seçilerek belirlenmiştir. Optimizasyon işlemi ile çalışılan moleküle ait geometrik parametreler elde edilmiştir. X-1şınları çalışması daha önceden yapılmış olan 4-Etoksi-3-Metoksibenzaldehit molekülüne ait geometrik parametreler ile kuramsal olarak elde edilen bağ uzunluğu, bağ açısı ve torsiyon açı değerlerinin birbirleriyle oldukça iyi bir uyum içinde olduğu bulunmuştur. Kimyasal aktivite hesaplamalarının amacı çalışılan molekülün elektrofilik ve nükleofilik doğasının belirlenerek kimyasal aktif bölgelerinin tayin edilmesidir. Öncü moleküler orbitaller olan HOMO ve LUMO enejileri ile yapının enerji aralığı belirlenir ve böylece optimize yapının kararlılığı, kinetik stabilitesi ve kimyasal aktiviteye yatkınlığı incelenmiş olur. Sertlik ve yumuşaklık verileri global kimyasal aktivite parametreleridir ve çalışılan molekül grubuna ait elektronegatiflik, kimyasal potansiyel, elektrofilik indeks ve maksimum yük transferi gibi parametrelerin belirlenmesinde öncü rol oynar. Bunların yanı sıra lokal kimyasal aktivite hesaplamaları moleküler elektrostatik potansiyel haritası, Mulliken ve doğal popülasyon yüklerini ve Fukui fonksiyonlarının belirlenmesini içerir. Doğal bağ orbital (NBO) hesaplaması ile hiperkonjugatif etkileşim enerjisi, atomlara ait doluluk oranları ve moleküler geçiş durumları belirlenmiştir. Elektrofilik merkezli yük transferi ile DNA bazlarının çalışılan molekül ile etkileşimlerini ve yük geçişlerini belirleyerek elektrofilik ve nükleofilik doğasının belirlenmesini amaçlamaktadır. Ayrıca ikinci dereceden lineer olmayan optik özellikler ise kutuplanabilirlik ve hiperkutuplanabilirlik parametreleri ile belirlenmiş ve çalışılan molekülün optik materyal olma eğilimi incelenmiştir.

\section{Materyal ve Metot}

Son yıllarda hesaplamalı yöntemler moleküler seviyedeki davranışların aydınlatılmasında ve tahmin edilmesinde sıkça kullanılmaktadır. Bu sayede moleküllerin davranışları deney yapılmadan tahmin edilebilmektedir. YFT, ab-initio, moleküler mekanik ve bazı yarı-deneysel yöntemler eczacılık, farmakoloji ve malzeme mühendisliği alanlarında moleküler özelliklerinin araştırılmasında 
sıklıkla kullanılmaktadır. Bu kapsamda, kuramsal hesaplamalardan Yoğunluk Fonksiyoneli Kuramı (YFK) kullanılarak, deneysel verileri desteklemek ve deneysel olarak elde edilemeyen elektronik özellikler, enerji, dipol moment, kimyasal aktivite eğilimleri, moleküler elektrostatik potansiyel (MEP), sınır orbitalleri, sertlik ve yumuşaklık bilgileri, elektrofilik ve nükleofilik yatkınlık bölgeleri, yapıların optik materyal olma eğilimleri (NLO) analizi gibi birçok özellik hakkında bilgiye ulaşılması hedeflenmektedir.

Hesaplamalı kimya alanında en çok tercih edilen ve kullanılan yöntem yoğunluk fonksiyonel kuramıdır (YFK). YFK çok büyük moleküllerin enerji değerlerinin ve moleküllerin geometrik parametrelerinin hesaplanmasında kullanışı bir yöntemdir. YFK modelinde ise tam dalga fonksiyonlarının bilinmesi ideal çok elektronlu sisteme uyan bir hamiltoniyenle başlar. YFK'ya ait tüm hesaplamalar Gaussian09 programı (Frisch ve ark., 2009) kullanılarak elde edilmiştir. Kuramsal hesaplamaların ilk olarak çalışılan moleküllerin optimizasyonu ile başlar. Optimizasyon sonucunda elde edilen geometrik verilerin X-1şını kırınımı yöntemi sonucunda elde edilen verilerle uyumu kuramsal methodun ve seçtiğimiz yöntemin doğruluğunu belirler. $\mathrm{Bu}$ çalışmada seçilen YFK/B3LYP/6-311G(d,p) sonuçları X-ışınları kırınımı yöntemiyle elde edilen geometrik parametreleri başarılı bir şekilde temsil etmiştir. Bu aşamadan sonra enerjiden elde edilen özellikler ile çalışılan molekülün moleküler ve kimyasal özelliklerine ulaşılması amaçlanmıştır.

\section{Bulgular ve Tartışma}

\subsection{Optimize Yapı}

4-etoksi-3-metoksibenzaldehit molekülüne ait optimize yapı görünümü ve X-1şını (Leka ve ark., 2013) çalışması sonucunda elde edilen moleküler yapı görünümü Şekil 1'de verilmiştir. Moleküle ait bazı seçilmiş bağ uzunluğu, bağ açısı ve torsiyon açı değerleri Tablo 1'de YFK/B3LYP/6-311G(d,p) ve X-ışını kırınımı deneyinden elde edilmiş olan verilerle karşılaştırmalı olarak verilmiştir. YFK sonuçlarının X-ışını kırınımı verilerini başarılı bir şekilde temsil ettiği görülmektedir.

Moleküle ait C1-C2, C1-O1, C4-O2, C8-O2, C5-O3, C9-O3 ve C9-C10 bağ açı11 değerleri sirasiyla deneysel olarak 1.457(2), 1.204(2), 1.3618(18), 1.421(2), 1.355(2), 1.433(2), 1.484(3) ̊ [1], kuramsal olarak ise sırasıyla 1.54, 1.27, 1.43, 1.43, 1.35, 1.43, 1.47 Å olarak elde edilmiştir. 


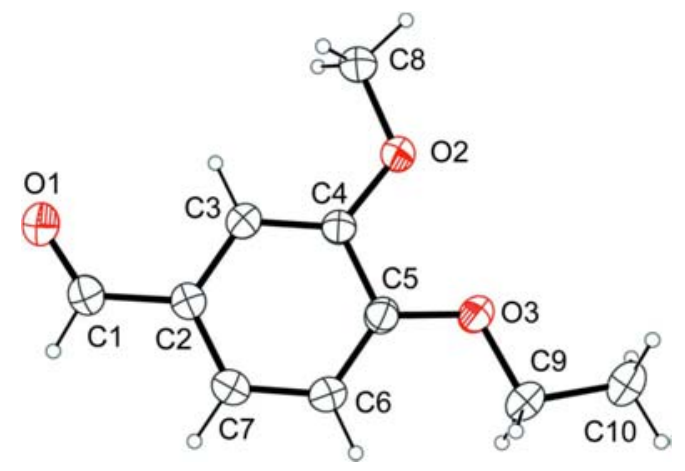

a)

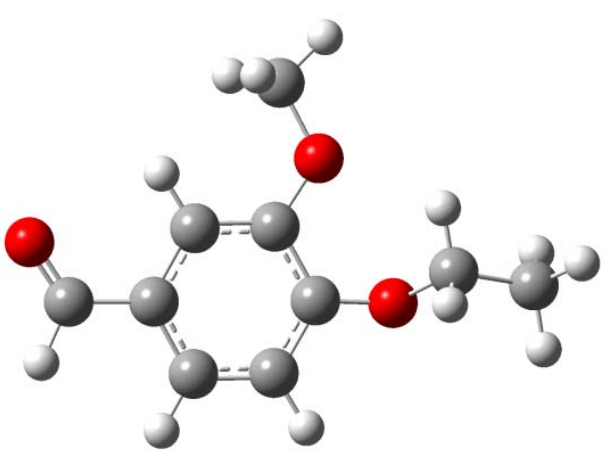

b)

Şekil 1. 4-etoksi-3-metoksibenzaldehit molekülüne ait a) X-ışını kırınımı deneyi [1] ve b) optimize yapı görünümü.

Geometrik parametrelerde gözlenen ufak farklılıkların sebebinin, kuramsal hesaplamaların moleküler yapıyı gaz fazında, yalıtılmış bir ortamda ve tüm etkileşimleri dikkate almadan hesaplamasından kaynaklanmasından olduğu öngörülmektedir.

Tablo 1. 4-etoksi-3-metoksibenzaldehit molekülüne ait bazı deneysel ve kuramsal geometrik parametreler.

\begin{tabular}{cccc}
\hline $\begin{array}{c}\text { Bağ } \\
\text { açısı }^{\circ} \text { ve torsiyon açısı }\end{array}$ & $\begin{array}{c}\text { X-ışımı kırınımı (deneysel) } \\
\text { (Leka ve ark., 2013) }\end{array}$ & YFK/B3LYP/6-311G(d,p) \\
\hline C1-C2 & $1.457(2)$ & 1.54 \\
C1-O1 & $1.204(2)$ & 1.27 \\
C4-O2 & $1.3618(18)$ & 1.43 \\
C8-O2 & $1.421(2)$ & 1.43 \\
C5-O3 & $1.355(2)$ & 1.35 \\
C9-O3 & $1.433(2)$ & 1.43 \\
C9-C10 & $1.484(3)$ & 1.47 \\
O1-C1-C2 & $126.0(2)$ & 128.9609 \\
C4-O2-C8 & $117.27(13)$ & 109.5 \\
C5-O3-C9 & $117.93(14)$ & 109.5 \\
O3-C9-C10 & $108.51(16)$ & 108.58 \\
O1-C1-C2-C3 & $-2.7(3)$ & 7.4378 \\
C8-O2-C4-C5 & $-179.05(16)$ & 177.0815 \\
C5-O3-C9-C10 & $177.85(15)$ & 178.72 \\
\hline
\end{tabular}

\subsection{Lokal Kimyasal Aktivite: Moleküler Elektrostatik Potansiyel}

Moleküler elektrostatik potansiyel elektron yoğunluğu ile ilgilidir ve elektrofilik doğa, nükleofilik reaksiyonlar ve hidrojen bağ etkileşimleri için oldukça iyi bir açıklayıcıdır. Moleküler elektrostatik potansiyel yüzeyleri renk kodları ile tanımlanır. En negatif bölgeler kırmızı ile temsil edilmekte ve bu bölgeler elektrofilik reaksiyonları tanımlarken, mavi ve yeşil renk en pozitif bölgeleri ve nükleofilik baskın bölgeleri temsil ettiği öngörülmektedir (Demircioğlu ve ark., 2015). Şekil 2'den görüldüğü üzere optimize yapıda elektrofilik reaksiyon bölgeleri O1, O2 ve O3 atomları üzerinde 
yerelleşmiştir. Nükleofilik reaksiyonları tanımlayan maksimum pozitif bölgeler fenil halkası ve metil grubu üzerindeki hidrojen atomları üzerinde yoğunlaşmıştır. MEP haritasındaki bu sonuçlara göre, negatif potansiyel bölgesi elektronegatif atomlar üzerindeyken pozitif potansiyel bölgesi, hidrojen ve hidrojen atomlarının etrafındadır. Bu yerler bileşiğin kovalent olmayan etkileşimlere sahip olabileceği bölgeler hakkında bilgi verir. MEP ayrıca molekül içi ve moleküller arası etkileşimler ile tanımlanan bölgeler için oldukça iyi sonuçlar vermektedir. Şekil 2b'de görüldüğü gibi MEP kontör yüzeyinde elektron yoğunluğunun iki boyutlu yüzey eğrileri şeklinde verilmiş gösterimidir.

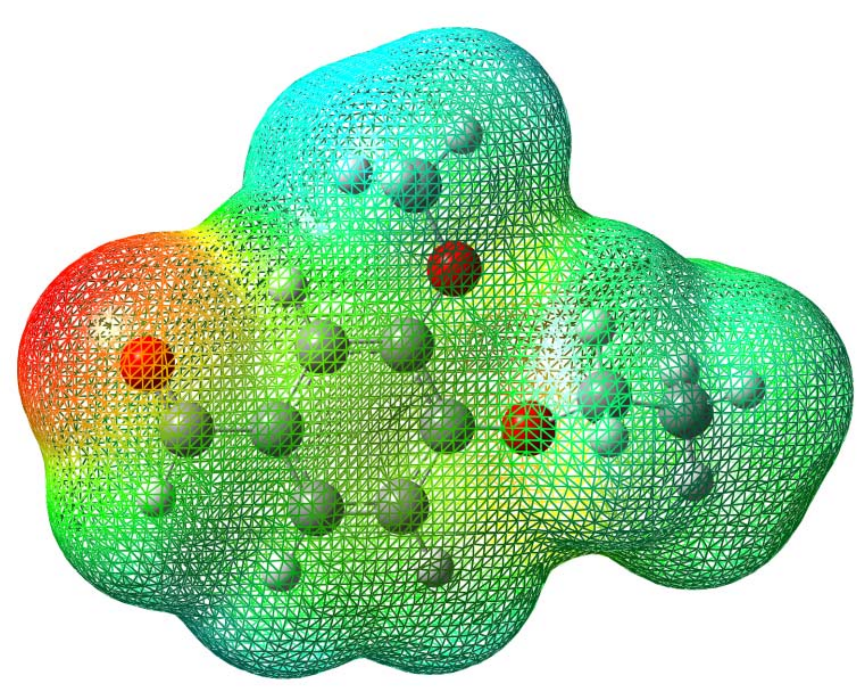

a)

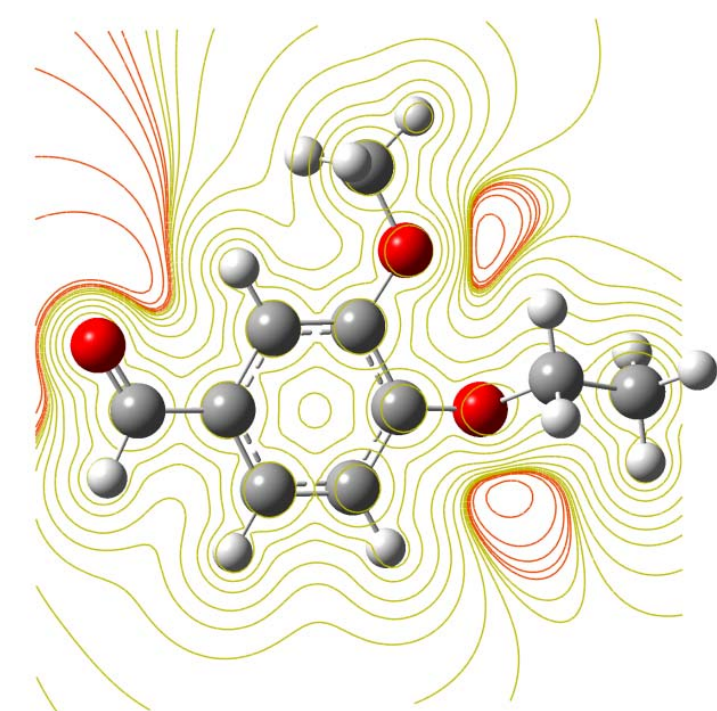

b)

Şekil 2. Optimize yapıya ait a) MEP ve b) MEP kontör yüzeyi.

\subsection{Lokal Kimyasal Aktivite: Net Yükler}

Net yük analizinde en sık kullanılan yöntemler Mulliken popülasyon (MP) ve doğal popülasyon (NP) yük analizidir. Mulliken popülasyon yöntemi en eski ve en yaygın olarak kullanılan yöntemlerden biridir. $\mathrm{Bu}$ yöntem atomik orbitallerin lineer kombinasyonu sonucu moleküler orbitallerin elde edilmesine dayanır. Tam olarak tatmin edici sonuçlar vermemesinin sebebi, dalga fonksiyonlarının atomlara dağılımını yaparken iki orbitalin çakışmasının söz konusu olduğu yerleri eşit olarak dağıtmasından kaynaklanır. Ancak elektron yoğunluğundan farklı olarak atomik yüklerin kuantum mekaniksel olarak gözlenebilir bir nicelik olmaması, dolayısıyla kesin hesaplama beklenemez. Bu sebeple bu niceliği hesaplamak için geliştirilen bütün metotlar belli ölçülerde bazı ihmalleri içerebilmektedir. Atomlara ait yüklerin belirlenmesi ve elektrofilik ve nükleofilik doğanın anlaşılmasında kullanılmasında yeterli sonuçlar verdiği literatürde öngörülmüştür (Pir Gümüş ve Atalay, 2017). Doğal popülasyon yük analizi de Mulliken'e benzer kuramsal bir hesaplama yöntemidir. Doğal popülasyon yükleri Doğal bağ orbital (NBO) analizi sonucunda hesaplanmaktadır. 
Her iki yöntemde elde edilen net yük değerleri birbiri ile oldukça iyi bir uyuma sahiptir. Tablo 2'de her iki yönteme ait net yükler optimize yapıya ait her bir atom için karşılaştırmalı olarak verilmiştir. En negatif yükler C2, C3, C6, C7, C8, C9, C10, O1, O2 ve O3 atomları üzerinde yerelleşirken, en pozitif yükler ise C1, C4, C5 ve tüm hidrojen atomlarının üzerinde olduğu Tablo 2'de görülmektedir. Net yük analizi sonucunda elde edilen en pozitif ve en negatif bölgeler MEP haritasını destekler yönde elde edilmiştir.

Tablo 2. Optimize yapıya ait Mulliken popülasyon (MP) ve doğal popülasyon (NP) net yük verileri.

\begin{tabular}{rccclc}
\hline Atom & MP & NP & Atom & \multicolumn{1}{c}{ MP } & NP \\
\hline C1 & 0.179014 & 0.44497 & H1 & 0.112695 & 0.0972 \\
C2 & -0.128214 & -0.13297 & H3 & 0.14586 & 0.24851 \\
C3 & -0.075268 & -0.25672 & H6 & 0.091312 & 0.20834 \\
C4 & 0.078622 & 0.22995 & H7 & 0.095167 & 0.20835 \\
C5 & 0.170332 & 0.26123 & H8a & 0.116513 & 0.13374 \\
C6 & -0.072147 & -0.23019 & H8b & 0.146431 & 0.25401 \\
C7 & -0.055489 & -0.18846 & H8c & 0.119754 & 0.26839 \\
C8 & -0.256465 & -0.34138 & H9a & 0.155592 & 0.35310 \\
C9 & -0.077659 & -0.22834 & H9b & 0.227847 & 0.15630 \\
C10 & -0.487001 & -0.63372 & H10a & 0.083688 & 0.21221 \\
O1 & -0.297460 & -0.51184 & $\mathbf{H 1 0 b}$ & 0.213604 & 0.22645 \\
O2 & -0.279844 & -0.52199 & $\mathbf{H 1 0 c}$ & 0.054289 & 0.26109 \\
O3 & -0.261180 & -0.51830 & & & \\
\hline
\end{tabular}

\section{4. Öncü Moleküler Orbitaller ve Global Kimyasal Aktivite Parametreleri}

Öncü moleküler orbitaller moleküllerin moleküler reaktifliği, 1şık soğurabilirliği, optik ve elektrik özelliklerin tanımlanmasında kullanılmaktadır. Öncü moleküler orbitaller olan HOMO, elektronlar tarafından işgal edilmiş en dış molekül orbital olup elektron vericisi gibi davranırken, LUMO elektronlar tarafından işgal edilmemiş ilk boş molekül orbital ve bir elektron alıcısı gibi davranmaktadır. $\mathrm{Bu}$ nedenle HOMO enerjisi doğrudan iyonlaşma potansiyeli ile ilgilidir ve molekülün elektron verme yeteneğini temsil eder. LUMO enerjisi ise doğrudan elektron ilgisi ile ilgilidir ve molekülün elektron alma yeteneğini temsil eder. HOMO ve LUMO arasındaki enerji fark1, molekülün kimyasal kararlılığının göstergesidir (Tanak ve ark., 2010). Optimize yapıya ait HOMO ve LUMO yüzey görünümleri Şekil 3'de verilmiştir. 


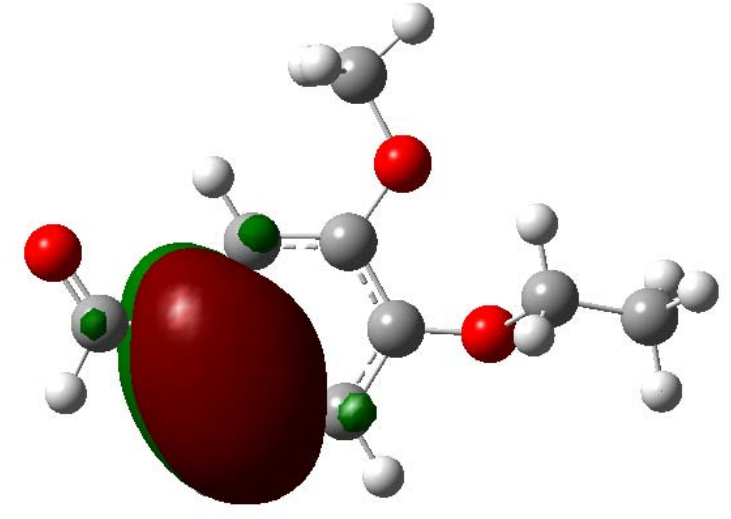

a)

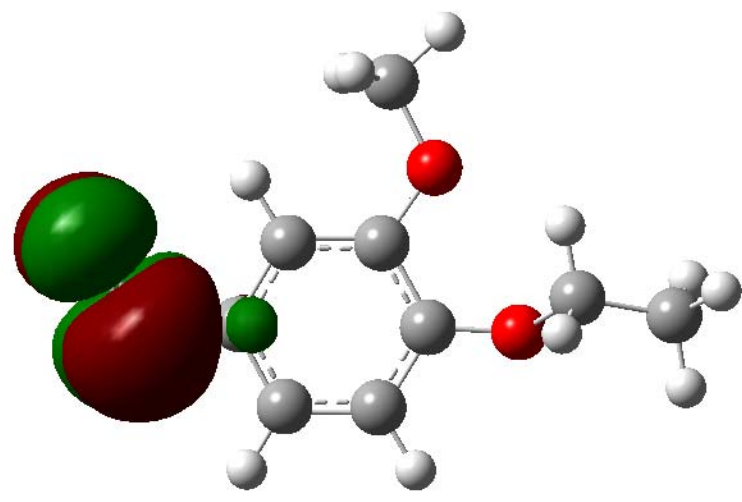

b)

Şekil 3. Optimize yapıya ait a) HOMO ve b) LUMO yüzey görünümleri.

Sertlik değeri molekül içerisindeki yük transferinin engellenmesinin bir ölçüsüdür. Kimyasal sertliği yüksek olan moleküllerin molekül içi yük transferi azdır veya hiç gerçekleşmemektedir. Optimize moleküle ait HOMO, LUMO enerjisi ve enerji aralığı sırasıyla $-7.0419 \mathrm{eV},-0.387 \mathrm{eV}$ ve $6.65 \mathrm{eV}$ olarak hesaplanmıştır. Yüksek enerji aralığı yapının oldukça yüksek sertlik $3.325 \mathrm{eV}$ ve düşük yumuşaklık $0.150(\mathrm{eV})^{-1}$ verilerine sahip olması ile düşük kimyasal aktivite ve yüksek kinetik stabilite ile oldukça kararlı olduğunu göstermektedir. Bunlara ek olarak elektrofilik indeks $2.074 \mathrm{eV}$, kimyasal potansiyel $-3.714 \mathrm{eV}$ ve maksimum yük transfer parametresi ise 0.558 olarak bulunmuştur.

\subsection{DNA bazları ile Elektrofilik-merkezli Yük Transferi (ECT) Analizi}

Elektrofilik-merkezli yük transfer (ECT) yöntemi incelenen molekül ve DNA bazlarının (adenin, guanin, sitozin ve timin) elektrofilik ve nükleofilik davranışlarını ortaya koyan önemli fiziksel ve kimyasal bir fonksiyondur (Demircioğlu ve ark., 2019). Hesaplanan ECT değeri sifırdan büyükse, yükler bazdan fonksiyonel gruba akmaktadır. Bunun aksine, ECT değeri sıfırdan küçük ise, yükler fonksiyel gruptan baz yapısına hareket etme eğilimindedir. $N$ elektronlu nötr gruba ait geometriler nötral, anyonik ve katyonik durum için iyonizasyon potansiyel enerjisi $I P=[\mathrm{E}(N-1)-\mathrm{E}(N)]$ ve elektron çekim enerjisi $E A=[\mathrm{E}(N)-\mathrm{E}(N+1)]$ ile hesaplanmaktadır. ECT değerini etkileşen sistemlerin $\Delta N_{\max }$ farkları belirlemektedir. İncelenen molekülü A, DNA bazlarını (adenin, guanin, sitozin ve timin) B olarak ele alırsak, ECT > 0 olduğunda yük geçişi B' den A' ya; ECT < 0 olduğunda ise A' dan B' ye olmaktadır. ECT yöntemiyle çalışılan molekül ve DNA bazlarının birbirleriyle olan yük transferi açıklanmış olmaktadır. Yük transferi ile ilgili eşitlikler:

$\mathrm{ECT}=\left(\Delta \mathrm{N}_{\max }\right)_{\mathrm{A}}-\left(\Delta \mathrm{N}_{\max }\right)_{\mathrm{B}}$ 
olarak verilir. Hesaplanan ECT değerleri adenin, sitozin, guanin ve timin için sırasıyla 0.2421, 0.2021, 0.3341ve -0.4289 olarak bulunmuştur (Tablo 3). Bu sonuçlar ECT >0 değerlerinde adenin, sitozin ve guanin DNA bazlarından çalışılan yapıya yük geçişi olduğunu ifade etmektedir. Bunun aksine ECT $<0$ olan timin DNA bazına ise molekülden yük transferi olmaktadır. Bu sebeble, adenin, sitozin ve guanin DNA bazlarında elektron verici (elektrofilik), incelenen molekül ise elektron alıcı (nükleofilik) bir doğaya sahip olduğu öngörülmüştür. Hesaplanan sonuçlara göre optimize yapı timin DNA bazı ile en çok etkileşime (yük transferi) sahiptir.

Tablo 3. Optimize yapı (A) ve DNA bazlarına (B) ait hesaplanan ECT yük transferi değerleri.

\begin{tabular}{lccccc}
\hline $\begin{array}{l}\text { Optimize yap1 } \\
\text { DNA Bazlar1 }\end{array}$ & $\begin{array}{c}I P \\
(\mathrm{eV})\end{array}$ & $\begin{array}{c}E A \\
(\mathrm{eV})\end{array}$ & $\begin{array}{c}\mu \\
(\mathrm{eV})\end{array}$ & $\begin{array}{c}\eta \\
(\mathrm{eV})\end{array}$ & $\Delta N_{\max }$ \\
\hline Optimize yap1 & -0.00442 & 0.3015016 & -0.14854 & -0.15296 & 0.9711 \\
Adenin & -1.271 & 8.144 & -3.436 & -4.708 & 0.729 \\
$\mathbf{E C T}=\mathbf{0 . 2 4 2 1}$ & & & & & \\
Sitozin & -1.115 & 8.568 & -3.726 & -4.841 & 0.769 \\
$\mathbf{E C T}=\mathbf{0 . 2 0 2 1}$ & & & & & \\
Guanin & -1.709 & 7.719 & -3.004 & -4.714 & 0.637 \\
$\mathbf{E C T}=\mathbf{0 . 3 3 4 1}$ & & & & & \\
Timin & 1.627 & 9.745 & -5.686 & -4.059 & 1.400 \\
$\mathbf{E C T}=\mathbf{0 . 4 2 8 9}$ & & & & & \\
\hline
\end{tabular}

\subsection{Lokal Kimyasal Aktivite: Fukui Fonksiyon (FF) Analizi}

Moleküle ait NPY yükleri, nötr, anyonik ve katyonik durum için hesaplandı. Hesaplanan net yüklerden her bir durum için ayrı ayrı Fukui fonksiyonları elde edildi. Hesaplamalar aşağıdaki eşitlikler kullanılarak yapıldı. Bu eşitliklerde $f_{k}^{+}(r), f_{k}^{-}(r)$ ve $f_{k}^{0}(r)$ fonksiyonları sırasıyla nükleofilik atağa, elektrofilik atağa ve serbest radikal atağa yatkınlığı öngörmemize yarayan parametrelerdir. Fukui fonksiyon analizi aracılığı ile çalışılan molekülün elektrofilik ve nükleofilik atağa yatkın bölgeleri belirlendi.

$$
\begin{gathered}
f_{k}^{+}(r)=q_{k}(r)(N+1)-q_{k}(r)(N) \\
f_{k}^{-}(r)=q_{k}(r)(N)-q_{k}(r)(N-1)
\end{gathered}
$$




$$
f_{k}^{0}(r)=\frac{1}{2}\left[q_{k}(r)(N+1)-q_{k}(r)(N-1)\right]
$$

Burada $q_{k}$ atomik yükleri, $(N),(N+1),(N-1)$, sırasıyla, nötr, anyonik ve katyonik kimyasal bölgeler için $k^{\prime} ı$ ncı atomik yükleri temsil etmektedir. Tablo $4^{\prime}$ e bakıldığında, $\Delta f_{k}(r)$, yapıya ait atomların elektrofilik ve nükleofilik doğasını belirleyen bir parametredir ve $\Delta f_{k}(r)=\left[f_{k}^{+}(r)-\right.$ $\left.f_{k}^{-}(r)\right]$ ile belirlenir (Yang ve Parr, 1985). Eğer $\Delta f_{k}(r)>0$ ise nükleofilik yatkınlık, $\Delta f_{k}(r)<0$ ise elektrofilik yatkınlık baskındır.

Tablo 4. NPA net yükünden elde edilmiş Fukui fonksiyon analiz değerleri

\begin{tabular}{ccccccc}
\hline Atom & $\boldsymbol{q}_{\boldsymbol{k}}^{-}$ & $\boldsymbol{q}_{\boldsymbol{k}}^{+}$ & $\boldsymbol{q}_{\boldsymbol{k}}^{\mathbf{0}}$ & $\boldsymbol{f}_{\boldsymbol{k}}^{-}$ & $\boldsymbol{f}_{\boldsymbol{k}}^{+}$ & $\Delta \boldsymbol{f}_{\boldsymbol{k}}(\boldsymbol{r})$ \\
\hline C1 & 0.24691 & 0.40116 & 0.41867 & 0.17176 & -0.01751 & -0.18927 \\
C2 & -0.18799 & -0.04732 & -0.15336 & 0.03463 & 0.10604 & 0.07141 \\
C3 & -0.34137 & -0.23361 & -0.24950 & 0.09187 & 0.01589 & -0.07598 \\
C4 & 0.27481 & 0.37078 & 0.28540 & 0.01059 & 0.08538 & 0.07479 \\
C5 & 0.16521 & 0.41872 & 0.27159 & 0.10638 & 0.14713 & 0.04075 \\
C6 & -0.26327 & -0.21828 & -0.23092 & 0.03235 & 0.01264 & -0.01971 \\
C7 & -0.23859 & -0.07796 & -0.17973 & 0.05886 & -0.25769 & -0.31655 \\
C8 & -0.18829 & -0.21592 & -0.19641 & -0.00812 & -0.01951 & -0.01139 \\
C9 & -0.00628 & -0.02043 & -0.00866 & -0.00238 & -0.01177 & -0.00939 \\
C10 & -0.58000 & -0.58845 & -0.58213 & -0.00213 & -0.00632 & -0.00419 \\
O1 & -0.68759 & -0.44046 & -0.53502 & 0.15257 & 0.09456 & -0.05801 \\
O2 & -0.55283 & -0.40822 & -0.43001 & 0.12282 & 0.02179 & -0.10103 \\
O3 & -0.59078 & -0.46901 & -0.49316 & 0.09762 & 0.02415 & -0.07347 \\
\hline
\end{tabular}

Tablo 4. incelendiğinde, 4-Etoksi-3-Metoksibenzaldehit molekülüne ait $\Delta f_{k}(r)<0$, yani elektrofilik baskın bölgeler $\mathrm{C} 1, \mathrm{C} 3, \mathrm{C} 6, \mathrm{C} 7, \mathrm{C} 8, \mathrm{C} 9, \mathrm{C} 10, \mathrm{O} 1, \mathrm{O} 2, \mathrm{O} 3$ atomları üzerinde, $\Delta f_{k}(r)>0$, yani nükleofilik baskın bölgeler ise $\mathrm{C} 2, \mathrm{C} 4, \mathrm{C} 5$ atomları üzerinde yoğunlaşmıştır. FF sonuçlarına göre çalışılan molekülün elektrofilik doğasının, nükleofilik ve nötr doğaya karşı daha baskın olduğu öngörülmektedir. 


\subsection{Doğal Bağ Orbital Analizi (NBO)}

Doğal bağ orbital (NBO) analizi moleküler sistemlerde molekül içi ve moleküller arası bağlanma, yük transferi ve konjuge etkileşimler çalışmak için etkili bir metottur. Büyük $\mathrm{E}^{(2)}$ değeri elektron alıcı ve elektron vericiler arasındaki etkileşimin daha şiddetli olduğunu gösterir. İşgal edilmiş Lewis-tipi NBO orbitalleri ve işgal edilmemiş non-Lewis orbitalleri arasındaki elektron yoğunluğunun delokalizasyonu, kararlı bir alıcı-verici etkileşimine karşılık gelir (Foster ve Weinhold, 1980). NBO metodunda stabilizasyon enerji değeri, alıcı elektron ile verici elektron arasındaki yoğun etkileşmeyi belirtir. $E^{(2)}$ stabilizasyon enerji değeri, değişken bir alıcı yörünge doluluk oranına, alıc1verici yörünge enerjisine ve NBO Fock-Matris elemanına bağlıdır. Stabilizasyon enerji $E^{(2)}$, $\mathrm{i}($ verici $) \rightarrow \mathrm{j}($ alıcı) dekolarizasyonu kullanılarak

Doğal bağ orbital (NBO) analizi moleküler sistemlerde molekül içi ve moleküller arası bağlanma ve yük transferi ya da konjugüye etkileşimler çalışmak için etkili bir metottur. Büyük $\mathrm{E}^{(2)}$ değeri elektron alıcı ve elektron vericiler arasındaki etkileşimin daha şiddetli olduğunu gösterir. İşgal edilmiş Lewis-tipi NBO orbitalleri ve işgal edilmemiş non-Lewis orbitalleri arasındaki elektron yoğunluğunun delokalizasyonu, kararlı bir alıcı-verici etkileşimine karşılık gelir. NBO metodunda stabilizasyon enerji değeri, alıcı elektron ile verici elektron arasındaki yoğun etkileşmeyi belirtir. $E^{(2)}$ stabilizasyon enerji değeri, değişken bir alıcı yörünge doluluk oranına, alıcı-verici yörünge enerjisine ve NBO Fock-Matris elemanına bağlıdır. Stabilizasyon enerji $E^{(2)}$, i(verici) $\rightarrow \mathrm{j}($ alıcı) dekolarizasyonu kullanılarak

$E^{(2)}=q_{i} \frac{F^{2}(i, j)}{\varepsilon_{j}-\varepsilon_{i}}$

eşitliği ile verilir. $q_{i}$ verici orbitalin doluluğu, $\varepsilon_{\mathrm{j}}$, $\varepsilon_{\mathrm{i}}$ diyagonal elemanlar (yörünge enerjileri), $F_{(\mathrm{i}, \mathrm{j})}$ ise diyagonal olmayan Fock matris elemanlarıdır. NBO analizi sonucunda, yapıya ait toplam Lewis etkileşimi \%95.484 (çekirdek, \%99.946; Lewis valans, \% 93.826) ve toplam Lewis olmayan etkileşim \%4.516 (Lewis olmayan Rydberg, \%0.355; Lewis olmayan valans, \%4.162) olarak elde edilmiştir.

Moleküller arası hiperkonjugatif etkileşimler bağ ve antibağ orbitalleri arasında orbitallerin örtüşmesiyle moleküler sistemin stabilizasyonuna sebep olarak moleküller arası yük transferine izin verir. $\mathrm{Bu}$ etkileşimler bağ karakterini zayıflatarak, antibağ orbitallerinde elektron yoğunluğunun artışına yol açar. $\mathrm{Bu}$, antibağ orbitallerinde elektron yoğunluğunun artışına yol açan etkileşimler $\pi(\mathrm{C} 3-\mathrm{C} 4) \rightarrow \pi^{*}(\mathrm{C} 5-\mathrm{C} 6) 21.24 \mathrm{kcal} / \mathrm{mol}, \pi(\mathrm{C} 3-\mathrm{C} 4) \rightarrow \pi^{*}(\mathrm{C} 7-\mathrm{C} 2) 19.16 \mathrm{kcal} / \mathrm{mol}, \pi(\mathrm{C} 5-\mathrm{C} 6) \rightarrow \pi^{*}(\mathrm{C} 3-$ C4) $20.29 \mathrm{kcal} / \mathrm{mol}, \pi(\mathrm{C} 5-\mathrm{C} 6) \rightarrow \pi^{*}(\mathrm{C} 7-\mathrm{C} 2) 20.81 \mathrm{kcal} / \mathrm{mol}, \pi(\mathrm{C} 7-\mathrm{C} 2) \rightarrow \pi^{*}(\mathrm{C} 3-\mathrm{C} 4) 21.36 \mathrm{kcal} / \mathrm{mol}$ ve $\pi(\mathrm{C} 7-\mathrm{C} 2) \rightarrow \pi^{*}(\mathrm{C} 5-\mathrm{C} 6) 19.36 \mathrm{kcal} / \mathrm{mol}$ olarak gözlenmiştir. 
Tablo 5. Optimize yapıya ait doğal bağ orbital analiz verileri.

\begin{tabular}{|c|c|c|c|c|c|c|c|c|}
\hline $\begin{array}{l}\text { Donör }(i) \\
(\text { doluluk })\end{array}$ & Tip & $\begin{array}{l}E D_{A}, \% \\
E D_{B}, \%\end{array}$ & $\begin{array}{l}\text { Akseptör }(j) \\
(\text { doluluk })\end{array}$ & Tip & $\begin{array}{l}E D_{A} \\
\% \\
E D_{B} \\
\%\end{array}$ & $\begin{array}{l}E^{(2) a} \\
(k c a l / m o l)\end{array}$ & $\begin{array}{l}E_{j}-E_{i}^{b} \\
\text { (a.u.) }\end{array}$ & $\begin{array}{l}F(i j)^{c} \\
(\text { a.u. })\end{array}$ \\
\hline BD C3-C4 & \multirow[t]{2}{*}{$\sigma$} & 49.94 & $\mathrm{BD} * \mathrm{C} 4-\mathrm{C} 5$ & \multirow[t]{2}{*}{$\sigma^{*}$} & 49.31 & \multirow[t]{2}{*}{4.88} & \multirow[t]{2}{*}{1.28} & \multirow[t]{2}{*}{0.071} \\
\hline (1.97472) & & 50.06 & $(0.03837)$ & & 50.69 & & & \\
\hline $\mathrm{BD} C 3-\mathrm{C} 4$ & \multirow[t]{2}{*}{$\pi$} & 48.91 & $\mathrm{BD} * \mathrm{C} 5-\mathrm{C} 6$ & \multirow{2}{*}{$\pi^{*}$} & 50.96 & \multirow{2}{*}{21.24} & \multirow[t]{2}{*}{0.30} & \multirow[t]{2}{*}{0.071} \\
\hline (1.67006) & & 51.09 & $(0.35893)$ & & 49.04 & & & \\
\hline $\mathrm{BD} C 3-\mathrm{C} 4$ & \multirow[t]{2}{*}{$\pi$} & 48.91 & $\mathrm{BD}^{*} \mathrm{C} 7-\mathrm{C} 2$ & \multirow[t]{2}{*}{$\pi^{*}$} & 51.64 & \multirow[t]{2}{*}{19.16} & \multirow[t]{2}{*}{0.30} & \multirow[t]{2}{*}{0.069} \\
\hline (1.67006) & & 51.09 & $(0.38072)$ & & 48.36 & & & \\
\hline $\mathrm{BD} C 3-\mathrm{C} 2$ & \multirow[t]{2}{*}{$\sigma$} & 49.95 & $\mathrm{BD} * \mathrm{C} 4-\mathrm{O} 2$ & \multirow[t]{2}{*}{$\sigma^{*}$} & 66.65 & \multirow[t]{2}{*}{4.17} & \multirow[t]{2}{*}{0.98} & \multirow[t]{2}{*}{0.057} \\
\hline (1.96684) & & 50.05 & $(0.04812)$ & & 33.35 & & & \\
\hline $\mathrm{BD}$ C3-H3 & \multirow[t]{2}{*}{$\sigma$} & 62.70 & $\mathrm{BD} * \mathrm{C} 7-\mathrm{C} 2$ & $\sigma^{*}$ & 50.66 & 4.54 & 1.08 & 0.063 \\
\hline (1.97219) & & 37.30 & $(0.02276)$ & & 49.34 & & & \\
\hline BD C5-C6 & $\pi$ & 49.04 & $\mathrm{BD} * \mathrm{C} 3-\mathrm{C} 4$ & $\pi^{*}$ & 51.09 & 20.29 & 0.28 & 0.068 \\
\hline$(1.65272)$ & & 50.96 & $(0.37306)$ & & 48.91 & & & \\
\hline BD C5-C6 & $\pi$ & 49.04 & $\mathrm{BD} * \mathrm{C} 7-\mathrm{C} 2$ & $\pi^{*}$ & 51.64 & 20.81 & 0.29 & 0.070 \\
\hline$(1.65272)$ & & 50.96 & $(0.38072)$ & & 48.36 & & & \\
\hline $\mathrm{BD}$ C5-O3 & $\sigma$ & 32.93 & $\mathrm{BD} * \mathrm{C} 3-\mathrm{C} 4$ & $\sigma^{*}$ & 50.06 & 1.93 & 1.33 & 0.045 \\
\hline$(1.97523)$ & & 67.07 & $(0.02711)$ & & 49.94 & & & \\
\hline $\mathrm{BD} C 7-\mathrm{C} 2$ & $\sigma$ & 49.34 & $\mathrm{BD} * \mathrm{C} 1-\mathrm{O} 1$ & $\sigma^{*}$ & 35.09 & 1.11 & 1.20 & 0.033 \\
\hline (1.97401) & & 50.66 & $(0.00420)$ & & 64.91 & & & \\
\hline $\mathrm{BD} C 7-\mathrm{C} 2$ & $\pi$ & 49.36 & $\mathrm{BD} * \mathrm{C} 3-\mathrm{C} 4$ & $\pi^{*}$ & 51.09 & 21.36 & 0.27 & 0.069 \\
\hline (1.65357) & & 51.64 & $(0.37306)$ & & 48.91 & & & \\
\hline BD C7-C2 & $\pi$ & 49.36 & $\mathrm{BD} * \mathrm{C} 5-\mathrm{C} 6$ & $\pi^{*}$ & 50.96 & 19.36 & 0.28 & 0.066 \\
\hline (1.65357) & & 51.64 & $(0.35893)$ & & 49.04 & & & \\
\hline BD C7-C2 & $\sigma$ & 49.36 & $\mathrm{BD} * \mathrm{C} 1-\mathrm{H} 1$ & $\sigma^{*}$ & 44.32 & 1.10 & 0.95 & 0.031 \\
\hline (1.65357) & & 51.64 & $(0.02907)$ & & 55.68 & & & \\
\hline $\mathrm{BD}$ O3-C9 & $\sigma$ & 67.48 & $\mathrm{BD}^{*} \mathrm{C} 9-\mathrm{C} 10$ & $\sigma^{*}$ & 47.49 & 7.71 & 1.31 & 0.091 \\
\hline (1.92874) & & 32.52 & $(0.03066)$ & & 52.51 & & & \\
\hline BD C9-H9a & $\sigma$ & 46.87 & $\mathrm{RY}{ }^{*} \mathrm{H} 9 \mathrm{a}$ & - & - & 11.23 & 2.68 & 0.177 \\
\hline$(1.52660)$ & & 53.13 & $(0.00082)$ & & & & & \\
\hline BD C9-C10 & $\sigma$ & 52.51 & $\mathrm{BD} * \mathrm{C} 5-\mathrm{O} 3$ & $\sigma^{*}$ & 67.07 & 17.91 & 0.96 & 0.117 \\
\hline$(1.86004)$ & & 47.49 & $(0.12112)$ & & 32.93 & & & \\
\hline BD C8-H8a & $\sigma$ & 48.48 & $\mathrm{RY}{ }^{*} \mathrm{H} 8 \mathrm{a}$ & $\sigma^{*}$ & 41.02 & 9.84 & 2.16 & 0.143 \\
\hline$(1.63737)$ & & 51.52 & $(0.00702)$ & & 58.98 & & & \\
\hline $\mathrm{CR} C 1$ & - & - & $\mathrm{BD}^{*} \mathrm{C} 1-\mathrm{H} 1$ & $\sigma^{*}$ & 44.32 & 2.01 & 10.81 & 0.132 \\
\hline (1.99894) & & & $(0.02907)$ & & 55.68 & & & \\
\hline CR C10 & - & - & $\mathrm{BD} * \mathrm{C} 10-\mathrm{H} 10 \mathrm{~b}$ & $\sigma^{*}$ & 44.85 & 12.50 & 10.59 & 0.330 \\
\hline (1.99764) & & & $(0.06196)$ & & 55.15 & & & \\
\hline LP O3 & $n$ & - & $\mathrm{BD} * \mathrm{C} 10-\mathrm{H} 10 \mathrm{~b}$ & $\sigma^{*}$ & 44.85 & 21.57 & 1.04 & 0.136 \\
\hline$(1.86951)$ & & & $(0.06196)$ & & 55.15 & & & \\
\hline LP O2 & $n$ & - & $\mathrm{BD} * \mathrm{C} 3-\mathrm{C} 4$ & $\pi^{*}$ & 51.09 & 16.18 & 0.34 & 0.071 \\
\hline$(1.86561)$ & & & $(0.37306)$ & & 48.91 & & & \\
\hline LP O1 & $n$ & - & $\mathrm{BD}^{*} \mathrm{C} 1-\mathrm{H} 1$ & $\sigma^{*}$ & 44.32 & 12.36 & 0.96 & 0.099 \\
\hline$(1.91336)$ & & & $(0.02907)$ & & 55.68 & & & \\
\hline LP C10 & $n$ & - & $\mathrm{BD} * \mathrm{C} 5-\mathrm{O} 3$ & $\sigma^{*}$ & 67.07 & 13.42 & 0.47 & 0.072 \\
\hline$(1.84626)$ & & & $(0.12112)$ & & 32.93 & & & \\
\hline $\mathrm{BD} * \mathrm{C} 3-\mathrm{C} 4$ & $\pi^{*}$ & 51.09 & $\mathrm{BD} * \mathrm{C} 7-\mathrm{C} 2$ & $\pi^{*}$ & 51.64 & 252.49 & 0.01 & 0.083 \\
\hline$(0.37306)$ & & 48.91 & $(0.38072)$ & & 48.36 & & & \\
\hline
\end{tabular}

En güçlü etkileşim Tablo 5'de görüldüğü üzere $\pi(\mathrm{C} 3-\mathrm{C} 4) \rightarrow \pi^{*}(\mathrm{C} 7-\mathrm{C} 2)$ geçişiyle 252.49 kcal/mol olarak bulunmuştur. Yapıya ait moleküller arası hidrojen bağı yapan atomların yapmış olduğu alıcı elektron ile verici elektron arasındaki yoğun etkileşmeler $\sigma(\mathrm{C} 7-\mathrm{C} 2) \rightarrow \sigma^{*}(\mathrm{C} 1-\mathrm{H} 1)$, $\mathrm{CR}(\mathrm{C} 1) \rightarrow \sigma^{*}(\mathrm{C} 1-\mathrm{H} 1), \mathrm{CR}(\mathrm{C} 10) \rightarrow \sigma^{*}(\mathrm{C} 10-\mathrm{H} 10 \mathrm{~b})$ ve $\mathrm{n}(\mathrm{O} 3) \rightarrow \sigma^{*}(\mathrm{C} 10-\mathrm{H} 10 \mathrm{~b})$ arasinda, sirasiyla $1.10,2.01$, 
12.50 ve $21.57 \mathrm{kcal} / \mathrm{mol}$ değerlerindeki stabilizasyon enerjiyle gözlenmiştir. Bazı seçilmiş hiperkonjugatif etkileşimler, bağ ve antibağ orbitalleri arasında orbitallerin örtüşmesiyle meydana gelen stabilizasyon enerji değerleri Tablo 5'de verilmiştir.

\section{8. İkinci Dereceden Lineer Olmayan Optik Özellikler}

Yalıtılmış bir molekül üzerine dışarıdan bir elektrik alan uygulandığında, molekülün yük asimetrisi bozulur ve toplam dipol momenti yeniden şekillenir. Toplam dipol moment ifadesinde kalıcı dipol momentin yanı sıra birinci ve ikinci hatta daha üst mertebeden katkılar ortaya çıkar. Dışarıdan uygulanan elektrik alan zayıfsa lineer optik özellikleri temsil eden moleküler kutuplanabilirlik başka bir deyişle birinci dereceden kutuplanabilirlik, $\alpha$, dikkate alınırken uygulanan alan şiddetli ise lineer olmayan optik özellikleri temsil eden birinci dereceden hiperkutuplanabilirlik, başka bir deyişle ikinci dereceden kutuplanabilirlik, $\beta$, önemli hale gelir. Lineer olmayan optik özellik gösteren materyaller son yıllarda oldukça dikkat çekicidir. Bu materyaller, optik iletişimde, sinyal işlemede, optik hesaplamada, sensörlerde, optik bağlantı materyallerinin tasarımında ve diğer bir çok fotonik teknolojide etkili bir şekilde kullanılmaktadır (Nalwa ve Miyata, 1997).

4-Etoksi-3-Metoksibenzaldehit molekülünün moleküler kutuplanabilirlik ve ikinci dereceden kutuplanabilirlik değerleri YFK/B3LYP/6-311G(d,p) seviyesinde hesaplanmıştır. Hesaplanan moleküler kutuplanabilirlik , $\alpha$, ve ikinci dereceden kutuplanabilirlik , $\beta$, değerleri atomik birimden (a.u.) elektrostatik birime (e.s.b.) çevrilerek sırasıyla $18.7035 \AA^{3}, 7.6214 \times 10^{-30}$ esb olarak elde edilmiştir. Elde edilen $\beta$ değeri, molekülün optik bir materyal olmaya iyi bir aday olduğunu göstermektedir.

\section{Sonuçlar ve Öneriler}

4-etoksi-3-metoksibenzaldehit molekülünün lokal ve global kimyasal aktivite parametreleri kuramsal olarak YFK/B3LYP/6-31G(d,p) yöntemi ile incelenmiştir. İlk olarak molekülün minimum enerjili kararlı yapısının bulunabilmesi amacıyla, geometri optimizasyonu yapılmıştır. 4-etoksi-3metoksibenzaldehit molekülünün kuramsal olarak elde edilen geometrik parametreleri X-1şını [1] kırınımı deneyi sonucunda elde edilen verileri oldukça başarılı temsil etmiştir. Bu sonuç seçilen kuramsal yöntemin ve baz setinin iyi bir seçim olduğunu öngörmüştür. Global kimyasal aktivite parametreleri öncü moleküler orbital olan HOMO ve LUMO enerjilerinin hesaplanması sonucunda elde edilmiştir. Yüksek enerji aralığı optimize yapının oldukça yüksek sertlik $3.325 \mathrm{eV}$ ve düşük yumuşaklık $0.150(\mathrm{eV})^{-1}$ verilerine sahip olması ile düşük kimyasal aktivite ve yüksek kinetik stabilite ile oldukça kararlı olduğunu göstermektedir. Lokal kimyasal aktivite hesaplamaları MEP, net yükler 
ve Fukui fonksiyon analizlerini içerir ve çalışılan molekülün elektrofilik doğasının baskın olduğu ve oksijen atomları üzerinde negatif bölgelerin daha yoğun ve bu bölgelerin hidrojen bağlanmasında etkin olduğu öngörülmüştür. Doğal bağ orbital analizi ile stabilizasyon enerjisi, bağlardaki $\sigma$ ve $\pi$ bağları için bağ elektron bulunma yüzdeleri ve orbitallerin geçiş durumları incelenmiştir. ECT yöntemiyle incelenen molekülün DNA bazlarıyla (adenin, guanin, sitozin ve timin) olan yük transferi ve elektrofilik ve nükleofilik doğası incelenmiştir. Bunun sonucunda, ECT $>0$ değerlerinde adenin, sitozin ve guanin DNA bazlarından çalışılan yapıya yük geçişi olduğunu, bunun aksine ECT $<0$ olan timin DNA bazına ise molekülden yük transferi olduğu hesaplanmıştır. Böylece, adenin, sitozin ve guanin DNA bazları elektron verici (elektrofilik), incelenen molekülün ise elektron alıcı (nükleofilik) bir doğaya sahip olduğu ve optimize yapının en çok timin bazı ile etkileştiği bulunmuştur. İkinci dereceden lineer olmayan optik özellik (NLO) sonucunda hesaplanan yüksek hiperpolarizebilite $(\beta=$ $7.62 \times 10^{-30} \mathrm{esb}$ ) değeri ile optik bir materyal olmaya aday olduğu bulunmuştur.

\section{Kaynaklar}

Demircioğlu, Z., Albayrak Kaştaş, Ç. ve Büyükgüngör, O., (2015). Theoretical analysis (NBO, NPA, Mulliken Population Method) and molecular orbital studies (hardness, chemical potential, electrophilicity and Fukui function analysis) of(E)-2-((4-hydroxy-2-methylphenylimino)methyl)-3-methoxyphenol, J. Mol. Struct., 1091, 183-195.

Demircioğlu, Z., Ersanlı, C.C., Kaya Kantar, G., ve Saşmaz, S., (2019). Spectroscopic, Hirshfeld surface, Xray diffraction methodologies and local global chemical activity calculations of 5-(2-methoxy-4-(prop1-en-1-yl)phenoxy)pyrazine-2,3-dicarbonitrile. J. Mol. Struct. 1181, 25-37.

Foster, J.P., ve Weinhold, F., (1980). Natural hybrid orbitals, J. Am. Chem. Soc., 102, 7211-7218.

Frisch, M.J., Trucks, G.W., Schlegel, H.B., Scuseria, G.E., Robb, M.A., Cheeseman, J.R., Scalmani, G., Barone, V., Mennucci, B., Petersson, G.A., Nakatsuji, H., Caricato, M., Li, X., Hratchian, H.P., Izmaylov, A.F., Bloino, J., Zheng, G., Sonnenberg, J.L., Hada, M., Ehara, M., Toyota, K., Fukuda, R., Hasegawa, J., Ishida, M., Nakajima, T., Honda, Y., Kitao, O., Nakai, H., Vreven, T., Montgomery Jr., J.A., Peralta, J.E., Ogliaro, F., Bearpark, M., Heyd, J.J., Brothers, E., Kudin, K.N., Staroverov, V.N., Kobayashi, R., Normand, J., Raghavachari, K., Rendell, A., Burant, J.C., Iyengar, S.S., Tomasi, J., Cossi, M., Rega, N., Millam, J.M., Klene, M., Knox, J.E., Cross, J.B., Bakken, V., Adamo, C., Jaramillo, J., Gomperts, R., Stratmann, R.E., Yazyev, O., Austin, A.J., Cammi, R., Pomelli, C., Ochterski, J.W., Martin, R.L., Morokuma, K., Zakrzewski, V.G., Voth, G.A., Salvador, P., Dannenberg, J.J., Dapprich, S., Daniels, A.D., Farkas, O., Foresman, J.B., Ortiz, J.V., Cioslowski, J. and D.J. Fox, (2009). Gaussian 09, Revision E.01, Gaussian, Inc., Wallingford CT.

Kubra, R., Murthy, P. \& Mohan Rao, J. (2013). In vitro Antifungal Activity of Dehydrozingerone and its Fungitoxic Properties. J. Food Sci. 78, M64-M69.

Leka, Z., Novakovic',S. B., Bogdanovic,' G. A., Muškinjac, J., ve Vukic'evic R. D., (2013). 4-Ethoxy-3methoxybenzaldehyde. Acta Cryst., E69, o1728.

Nalwa, H.S., ve Miyata, S., (1997). Non-linear Optics of Organic Molecules and Polymers. CRC Press, Boca Raton, FL, 611.

Pir Gümüss, H., Atalay, Y., (2017). 3-hidroksi-4-hidroksimiinometil-5-hidroksimetil-1,2-dimetilpiridinyum iyodid molekülünün geometrik yapısının incelenmesi. Sakarya Üniversitesi Fen Bilimleri Enstitüsü Dergisi, 21(3), 564-571.

Tanak, H., Ağar, A., ve Yavuz, M. (2010). Combined experimental and computational modeling studies on 4[(2-hydroxy-3-methylbenzylidene) amino]-1,5-dimethyl-2-phenyl-1,2-dihydro-3H-pyrazol-3-one. Int. J. of Quan. Chem., 111(9), $2123-2136$. 
Tatsuzaki, J., Bastow, K. F., Nakagawa-Goto, K., Nakamura, S., Itokawa, H. \& Lee, K.-H. (2006). Dehydrozingerone, chalcone, and isoeugenol analogues as in vitro anticancer agents. J. Nat. Prod.,69, $1445-1449$.

Yang, W. ve Parr, R. G. (1985). Hardness, softness, and the fukui function in the electronic theory of metals and catalysis. Proc. Natl. Acad. Sci., 82, 6723-6726. 